\title{
Sources of Sexual Knowledge for High School Students in Tokyo, Japan
}

\author{
Kaori Watanabe ${ }^{1 *}$, Hitomi Tanaka ${ }^{2}$, Yumiko Totsu ${ }^{1}$ \\ ${ }^{1}$ National College of Nursing Japan, Tokyo, Japan \\ ${ }^{2}$ Tokyo Medical University, Tokyo, Japan \\ Email: *kaori.w@me.com
}

How to cite this paper: Watanabe, K., Tanaka, H., \& Totsu, Y. (2018). Sources of Sexual Knowledge for High School Students in Tokyo, Japan. Creative Education, 9, 2394-2404.

https://doi.org/10.4236/ce.2018.915180

Received: October 10, 2018

Accepted: November 9, 2018

Published: November 12, 2018

Copyright $(9) 2018$ by authors and Scientific Research Publishing Inc. This work is licensed under the Creative Commons Attribution International License (CC BY 4.0).

http://creativecommons.org/licenses/by/4.0/

\section{c) (i) Open Access}

\begin{abstract}
This study is aimed to clarify the methods and sources from which high school students in Tokyo actually acquired sex information and the methods and sources from which they desired to acquire sex information. The participants of the study were selected from six public high schools in Tokyo, and were administered a survey at the time of their second grade from January to February 2017, and again at the time of their third grade from September to November 2017. We conducted self-administrated questionnaire-based surveys with 1073 students. Between the two surveys, at eight to ten weeks prior to the September/November survey, an educational intervention was presented to these subjects. Final analysis subjects totaled 1011 students at the second-grade and 936 students at the third-grade in school. Although many subjects responded that they received sex education, not so many of them actually had correct sexual knowledge. Most subjects, that is, both boys and girls at both second and third grades, thought sex information should be acquired from school, and significantly fewer considered the Internet as a source of sex information as compared to previous studies. Most subjects had high expectations that sex education would be taught at high school by teachers. One difference between boys and girls was that many girls responded that sex education should be acquired primarily from school, then secondarily from parents. Fewer subjects responded that sex education should be acquired from friends and the Internet. For the future, upskilling teachers and parents in sex education at school and home is expected.
\end{abstract}

\section{Keywords}

High School Students, Sexual Knowledge, Sources, Internet, Sex Education, Japan 


\section{Introduction}

In recent years, backed by the global trend of Information Technology (IT) progress, the penetration rate of personal computers, mobile phones, smart phones and internet is rapidly growing, and it has caused large changes in the environment of sex education (Arulogun, Ogbu, \& Dipeolu, 2016). As the internet rapidly expands, overflowing of information concurrently occurs. The information about sex is not an exception and contemporary young people have been exposed to massive unfiltered information because of their affinity for internet (Strasburger, Wilson, \& Jordan, 2009; Liliana Escobar-Chaves, Tortolero, Markham, Low, Eitel, \& Thickstun, 2005; Bleakley, Hennessy, Fishbein, \& Jordan, 2009). Also, most of parent generation of contemporary Japanese high school students are 40's and 50's who can be categorized in two groups: ones who understand the mechanism and safety of the Internet well and master it, and the other ones who are not acquainted with. Numerous research studies on adolescent sexuality and sexual information have been reported in advanced countries including Europe and the United States (Strasburger, Wilson, \& Jordan, 2009; Liliana Escobar-Chaves, Tortolero, Markham, Low, Eitel, \& Thickstun, 2005; Bleakley, Hennessy, Fishbein, \& Jordan, 2009; Stevens, Gilliard-Matthews, Dunaev, Todhunter-Reid, Brawner, \& Stewart, 2017; Buhi, Daley, Fuhrmann, \& Smith, 2009; Wartella, Rideout, Zupancic, Beaudoin-Ryan, \& Lauricella, 2015). There are a few studies conducted in Japan but some reports that Japanese high school students nowadays acquire sexual information are not from parents, school teachers, and medical professions but from friends and Internet (Song et al., 2012).

Adolescent sex behavior is at higher risk of causing unintended pregnancy and sexually transmitted diseases due to lack of information and immature awareness in comparison with the adult and it has been known to be a high risk factor for the future health issue such as infertility consequently (UNFPA, 2013; WHO, 2011; United Nations Department of Economic and Social Affairs Population Division, 2011). In Japan, healthy child-rearing for the next generation is an important national issue and decreasing artificial abortion rate of teenagers and sexually transmitted diseases prevalence rate of teenagers is listed in the targets of the national health measures and policies of "Healthy Parents and Children 21" set forth by the Ministry of Health, Labor and Welfare in 2001 (Japanese Ministry of Health, Labor and Welfare, 2012).

\section{Method}

\subsection{Subjects}

In January-February, 2017, we administered our survey to 1073 second grade students of six senior high schools in the Tokyo metropolitan area using the Japanese language version of the self-administered questionnaire (collection rate 
94.5\%). Excluding invalid responses without age and gender specified, analysis subjects were 518 boys, 493 girls, and the total of 1011 students (94.2\%). In September-November 2017, we conducted the same survey to the same students who became the third grade in school after intervention which was implemented eight-ten weeks prior to this survey (collection rate $89.1 \%$ ). Out of those, the final analysis subjects were 476 boys (50.9\%), 460 girls (49.1\%) and the total of 936 students $(87.2 \%)$. To acquire the average data of high school students in Tokyo, all six high schools were public, fulltime, comprehensive and coed with almost equal boys/girls ratio. In compliance with the Research Code of Ethics the names of the six high schools are withheld.

\subsection{Survey Contents}

In addition to the basic attributes, we conducted surveys on sexual knowledge through multiple choices questions on sexually transmitted diseases (Chlamydia, Gonorrhea, Venereal/Syphilis, HIV/AIDS, Hepatitis B, Trichomoniasis) of which symptom and incubation period can be explained and contraceptive methods (Condom, Oral Contraceptive Pill, Rhythm Method, Coitus interruptus/Pull-out Method, Intrauterine Contraceptive Device/IUD) of which method and efficacy can be explained and question with three multiple choices on the usage of condom. Also, means for acquiring information about sex (school, parents, siblings, friends, TV \& magazine, Internet) and means that should be considered to acquire the information were surveyed. Furthermore, we conducted surveys about presence or absence of sexual hang-ups, persons to consult about sexuality and physical issues, experience of receiving sex education, and confidence in sufficient knowledge about sex.

All surveys were done with the same questionnaire used at the second grade and the third grade times. Based on the questionnaire that was prepared in English by us then translated into Vietnamese by a translator and used in surveys in Vietnam in 2012 and 2014 (Watanabe, 2016; Watanabe, Kaneko, Fujita, \& Motohashi, 2014a; Watanabe, Saruta, \& Kato, 2014b), we translated the English version of questionnaire into Japanese and modified it complying with Japanese culture and climate after discussing with representatives and persons in charge of subject high schools (head of year, homeroom teacher, nursing or Yogo-teacher) and making further adjustments in 2016. A “Yogo" teacher is a special licensed educator in Japan who supports children's growth and development through health education and health services on the basis of principles of health promotion in all areas of educational activities in school (Japanese Association of "Yogo" Teacher Education). Then we completed the final questionnaire through a pilot study of 560 high school students in Tokyo and used it for this study. In this process we used the words and terms of the textbooks of high school health and physical education and homemaking courses approved by the Japan Ministry of Education, Culture, Sports, Science and Technology. 


\subsection{Contents of Intervention}

Eight-to-ten weeks prior to the survey described in (1) above, an educational intervention was performed on a class-by-class basis. The number of students in a class was 30 - 40 and one class-based-teacher was assigned in each class. The intervention was conducted in the manner of lecture for approximately 30 minutes (questions and answers time not included) by each class teacher and researchers as leaders with support of a nursing teacher and vice-principal with whom we discussed the intervention protocol beforehand. The intervention pamphlet which was based on survey results from their second year of high school was used. The pamphlet is four-pages in size of B4, and contents are as follows: 1) disclosure about survey results of the second grade high school students (only tabulation of all participants and undisclosed name of person and school), 2) the necessity of learning sex for high school students and responsibility for living as a member of society, 3) types of contraceptive methods and specific usage of them, 4) types, symptoms and incubation periods of sexually transmitted diseases, 5) appropriate usage of condom and reasons for encouraging use of condom.

\subsection{Analysis Method}

After simple tabulation, sexual knowledge and the acquisition methods of information about sex at the second grade times and the third grade times of the same students of the six senior high schools in Tokyo were compared with McNemar Test. Additionally, the correlation between presence or absence of sex education and sexual knowledge was analyzed with Spearman's Rank Correlation Coefficient Test. All analyses were computed using SPSS 24 (Chicago, IL) statistical software.

\subsection{Ethical Consideration}

This study was approved by the Ethical Review Board of the National Center for Global Health and Medicine (NCGM) which is the controlling organization of the National College of Nursing, Japan, under supervision of the Japanese Ministry of Health (Approval number: NCGM-G-002071-00). We had the cooperation of the high schools and obtained written informed consent from the participating students before conducting this survey.

\section{Result}

Of the analysis subjects, $99.6 \%$ were 16 - or 17 -year-old and $77.6 \%$ were from nuclear families. Table 1 shows the status of responses to questions about the usage of condom. The ratio of the subjects who knew about proper timing to wear condom and countermeasures when condom broken was over 50\% range in girls at both the second- and third-grade times but it was less than a half in boys and there was no significant difference between the second- and third-grade times in both boys and girls.

Table 2 shows the presence or absence of receiving sex education and the 
awareness of the level of own sex knowledge. The ratio of the subjects who responded "I've ever received sex education" was over 65\% in both boys and girls and the subjects who thought "I have a sufficient knowledge about sex" was around a half in boys but $40 \%$ range in girls at both the second- and third-grade times. The results of McNemer test showed no statistical significant difference due to their grades in school and in both boys and girls even though there was a difference shown ostensibly in girl's sex knowledge in Table 2.

Table 3 shows the relationship between the presence or absence of sex education and the awareness of sex knowledge. Although in both boys and girls and at both the grades in school a significant correlation was seen between the presence or absence of sex education and the awareness of sex knowledge, no significant correlation of the presence or absence of sex education with the actual level of sex knowledge except a weak correlation was seen with a knowledge about countermeasures at condom breakage in girls at the second-grade times.

Table 4 shows the status of sex knowledge. The only sexually transmitted disease that was known (in other words its symptom, incubation period, etc. can be explained) by a majority of the respondents was chlamydia infection in boys at both of the second- and third-grade times. However, as for the most diseases there was a significant difference between the second- and third-grade times with more respondents answered that they had sex knowledge at the third-grade times. Also, as to acquainted contraceptives methods (its method and contraceptive efficacy, etc. can be explained), over $90 \%$ of respondents knew condom and also over $70 \%$ of them knew oral-contraceptive pill in both boys and girls and at both the second- and third-grade times. Concerning these two items, significantly many boys responded that they had the knowledge at the third-grade times but no significant difference due to their grades in school was seen in girls.

Table 5 shows the ways and sources of acquiring the knowledge about sex. The most major way and source actually to acquire the knowledge about sex for both boys and girls and at both the second- and third-grade times was school with the percentage of $50 \%$ followed by friends and the Internet. Furthermore, the most ideal way and source to acquire the knowledge about sex was also a school for both boys and girls and at both the second- and third-grade times and followed by the Internet and friends for boys and parents, friends and the Internet for girls.

Table 1. Correct/Incorrect answers to questions on condom usage.

\begin{tabular}{ccccccc}
\hline & \multicolumn{4}{c}{ Boy } & & Girl \\
\cline { 2 - 6 } Variable & $2^{\text {nd }}$ Grade n (\%) & $3^{\text {rd }}$ grade n (\%) & $\begin{array}{c}\text { McNemar } \\
\text { Test }\end{array}$ & $2^{\text {nd }}$ Grade n (\%) & $\begin{array}{c}3^{\text {rd }} \text { grade n (\%) } \\
\text { McNemar } \\
\text { Test }\end{array}$ \\
\hline $\begin{array}{c}\text { Proper timing to wear a condom } \\
\text { (triple choices) } \\
\text { Correct answer }\end{array}$ & 484 & 448 & n.s. & 445 & 413 & n.s. \\
\hline
\end{tabular}




\section{Continued}

\begin{tabular}{|c|c|c|c|c|c|c|}
\hline Incorrect answer & $247(51.0)$ & $239(53.3)$ & & $192(43.1)$ & $194(47.0)$ & \\
\hline $\begin{array}{c}\text { Proper countermeasure to condom breakage } \\
\text { (triple choices) }\end{array}$ & 469 & 434 & \multirow{3}{*}{ n.s. } & 444 & 412 & \multirow{3}{*}{ n.s. } \\
\hline Correct answer & $144(30.7)$ & $137(31.6)$ & & $155(34.9)$ & $126(30.6)$ & \\
\hline Incorrect answer & $325(69.3)$ & $297(68.4)$ & & $289(65.1)$ & $286(69.4)$ & \\
\hline
\end{tabular}

The top of each item column is the total number of respondents. The significant level is 0.05 .

Table 2. Sex education and awareness of the level of own Sex Knowledge.

\begin{tabular}{|c|c|c|c|c|c|c|}
\hline \multirow[b]{2}{*}{ Variable } & \multicolumn{3}{|c|}{ Boy } & \multicolumn{3}{|c|}{ Girl } \\
\hline & $\begin{array}{c}2^{\text {nd }} \text { Grade } \\
\text { n (\%) }\end{array}$ & $\begin{array}{c}3^{\text {rd }} \text { grade } \\
\text { n }(\%)\end{array}$ & $\begin{array}{c}\text { McNemar } \\
\text { Test }\end{array}$ & $\begin{array}{c}2^{\text {nd }} \text { Grade } \\
\text { n (\%) }\end{array}$ & $\begin{array}{c}3^{\text {rd }} \text { grade } \\
\text { n }(\%)\end{array}$ & $\begin{array}{c}\text { McNemar } \\
\text { Test }\end{array}$ \\
\hline Have ever received sex education? & 504 & 473 & & 482 & 456 & \\
\hline Yes & $338(67.1)$ & $326(68.9)$ & n.s. & 356 (73.9) & $316(69.3)$ & n.s. \\
\hline Do you have a sufficient sexual knowledge? & 490 & 473 & & 473 & 453 & \\
\hline Yes & $258(52.7)$ & $233(49.3)$ & n.s. & $216(45.7)$ & $181(40.0)$ & n.s. \\
\hline No & $232(47.3)$ & $240(50.7)$ & & $257(54.3)$ & $272(60.0)$ & \\
\hline
\end{tabular}

The top of each item column is the total number of respondents. The significant level is 0.05 .

Table 3. Relationship between the presence or absence of Sex Education and awareness of Sex Knowledge (Spearman's Rank Correlation Coefficient).

\begin{tabular}{|c|c|c|c|c|c|c|c|c|c|c|c|c|c|}
\hline \multicolumn{2}{|l|}{ Gender } & \multicolumn{6}{|c|}{ Boy } & \multicolumn{6}{|c|}{ Girl } \\
\hline \multicolumn{2}{|c|}{ Variable } & \multicolumn{2}{|c|}{$\begin{array}{l}\text { Correct/Incorrect } \\
\text { on Proper timing } \\
\text { to wear a condom }\end{array}$} & \multicolumn{2}{|c|}{$\begin{array}{c}\text { Correct/Incorrect } \\
\text { on Proper } \\
\text { countermeasure to } \\
\text { condom breakage }\end{array}$} & \multicolumn{2}{|c|}{$\begin{array}{l}\text { I have a sufficient } \\
\text { sexual knowledge } \\
\text { or not. }\end{array}$} & \multicolumn{2}{|c|}{$\begin{array}{l}\text { Correct/Incorrect } \\
\text { on Proper timing } \\
\text { to wear a condom }\end{array}$} & \multicolumn{2}{|c|}{$\begin{array}{c}\text { Correct/Incorrect } \\
\text { on Proper } \\
\text { countermeasure to } \\
\text { condom breakage }\end{array}$} & \multicolumn{2}{|c|}{$\begin{array}{c}\text { I have a } \\
\text { sufficient sexual } \\
\text { knowledge or not. }\end{array}$} \\
\hline Grade & & $\begin{array}{l}2^{\text {nd }} \\
\text { Grade }\end{array}$ & $3^{\text {rd }}$ Grade & $\begin{array}{l}2^{\text {nd }} \\
\text { Grade }\end{array}$ & $3^{\text {rd }}$ Grade & $2^{\text {nd }}$ Grade & $3^{\text {rd }}$ Grade & $\begin{array}{c}2^{\text {nd }} \\
\text { Grade }\end{array}$ & $3^{\text {rd }}$ Grade & $\begin{array}{l}2^{\text {nd }} \\
\text { Grade }\end{array}$ & $3^{\text {rd }}$ Grade & $\begin{array}{l}2^{\text {nd }} \\
\text { Grade }\end{array}$ & $3^{\text {rd }}$ Grade \\
\hline Presence & Rs & 0.046 & 0.033 & 0.011 & 0.050 & $0.198^{* \star}$ & $0.241^{\star \star}$ & -0.006 & 0.039 & $0.111^{\star}$ & 0.036 & $0.138^{* *}$ & $0.217^{\star \star}$ \\
\hline $\begin{array}{c}\text { or Absence } \\
\text { of Sex }\end{array}$ & $P$ & 0.310 & 0.491 & 0.805 & 0.298 & 0.000 & 0.000 & 0.894 & 0.432 & 0.019 & 0.466 & 0.003 & 0.000 \\
\hline Education & $\mathrm{N}$ & 483 & 446 & 468 & 432 & 490 & 473 & 445 & 413 & 444 & 412 & 472 & 453 \\
\hline
\end{tabular}

**. Correlation is significant at the 0.01 level (2-tailed). *. Correlation is significant at the 0.05 level (2-tailed).

Table 4. Status of SexualKnowledge.

\begin{tabular}{|c|c|c|c|c|c|c|}
\hline \multirow[b]{2}{*}{ Variable } & \multicolumn{3}{|c|}{ Boy } & \multicolumn{3}{|c|}{ Girl } \\
\hline & $2^{\text {nd }}$ Grade $\mathrm{n}(\%)$ & $3^{\text {rd }}$ grade $n(\%)$ & $\begin{array}{c}\text { McNemar } \\
\text { Test }\end{array}$ & $2^{\text {nd }}$ Grade n (\%) & $3^{\text {rd }}$ grade $\mathrm{n}(\%)$ & $\begin{array}{c}\text { McNemar } \\
\text { Test }\end{array}$ \\
\hline $\begin{array}{l}\text { Acquainted Sexually } \\
\text { Transmitted Diseases }\end{array}$ & 510 & 475 & & 488 & 459 & \\
\hline Chlamydia & $260(51.0)$ & $262(55.2)$ & $<0.01$ & $156(32.0)$ & $157(34.2)$ & 0.049 \\
\hline Gonorrhea & $90(17.6)$ & $106(22.3)$ & n.s. & $39(8.0)$ & $67(14.6)$ & $<0.01$ \\
\hline Venereal/Syphilis & $150(29.4)$ & $183(38.5)$ & $<0.01$ & $83(17.0)$ & $106(23.1)$ & $<0.01$ \\
\hline
\end{tabular}




\section{Continued}

\begin{tabular}{|c|c|c|c|c|c|c|}
\hline HIV (AIDS) & $164(32.2)$ & $181(38.1)$ & n.s. & $110(22.5)$ & $118(25.7)$ & n.s. \\
\hline Hepatitis B & $62(12.2)$ & $87(18.4)$ & 0.02 & $67(13.7)$ & $73(15.9)$ & 0.04 \\
\hline Trichomoniasis & $23(4.5)$ & $49(10.3)$ & $<0.01$ & $16(3.3)$ & $35(7.6)$ & $<0.01$ \\
\hline $\begin{array}{c}\text { Acquainted } \\
\text { Contraceptive Methods }\end{array}$ & 510 & 475 & & 488 & 459 & \\
\hline Condom & $374(93.3)$ & 445 (93.7) & 0.03 & 447 (91.6) & $424(92.4)$ & n.s. \\
\hline Oral Contraceptive Pill & $374(73.3)$ & $360(75.8)$ & 0.03 & $385(78.9)$ & $359(78.2)$ & n.s. \\
\hline Rhythm Method & $68(13.3)$ & $94(19.8)$ & $<0.01$ & $39(8.0)$ & $60(13.1)$ & $<0.01$ \\
\hline $\begin{array}{l}\text { Coitus interruptus } \\
\text { (Pull-out Method) }\end{array}$ & $255(50.0)$ & $248(52.2)$ & $<0.01$ & $174(35.7)$ & $164(35.7)$ & 0.03 \\
\hline $\begin{array}{c}\text { Intrauterine Contraceptive } \\
\text { Device (IUD) }\end{array}$ & $138(27.1)$ & $143(30.2)$ & 0.03 & $139(28.5)$ & $139(30.3)$ & 0.03 \\
\hline
\end{tabular}

The top of each item column is the total number of respondents. The significant level is 0.05 .

Table 5. Ways and sources of acquiring sexualknowledge.

\begin{tabular}{|c|c|c|c|c|c|c|}
\hline \multirow[b]{2}{*}{ Variable } & \multicolumn{3}{|c|}{ Boy } & \multicolumn{3}{|c|}{ Girl } \\
\hline & $\begin{array}{c}2^{\text {nd }} \text { Grade } \\
\mathrm{n}(\%)\end{array}$ & $\begin{array}{c}3^{\text {rd }} \text { grade } \\
n(\%)\end{array}$ & $\begin{array}{c}\text { McNemar } \\
\text { Test }\end{array}$ & $\begin{array}{c}2^{\text {nd }} \text { Grade } \\
\mathrm{n}(\%)\end{array}$ & $\begin{array}{c}3^{\text {rd }} \text { grade } \\
\mathrm{n}(\%)\end{array}$ & $\begin{array}{c}\text { McNemar } \\
\text { Test }\end{array}$ \\
\hline Actual Source of Sexual Knowledge & 510 & 475 & & 488 & 458 & \\
\hline School & $229(44.9)$ & $205(43.2)$ & n.s. & $208(42.6)$ & $171(37.3)$ & n.s. \\
\hline Parents & $19(3.7)$ & $18(3.8)$ & n.s. & $29(5.9)$ & $34(7.4)$ & n.s. \\
\hline Brother/Sister & $17(3.3)$ & $12(2.5)$ & n.s. & $9(1.8)$ & $14(3.1)$ & n.s. \\
\hline Friends & $138(27.1)$ & $122(25.7)$ & n.s. & $93(19.1)$ & $87(19.0)$ & n.s. \\
\hline TV and Magazines & $39(7.6)$ & $45(9.5)$ & n.s. & $38(7.8)$ & $30(6.6)$ & n.s. \\
\hline Internet & $121(23.7)$ & $112(23.6)$ & n.s. & $58(11.9)$ & $61(13.3)$ & n.s. \\
\hline Others & $13(2.5)$ & $5(1.1)$ & n.s. & $10(2.0)$ & $4(0.9)$ & n.s. \\
\hline Ideal Source of Sexual Knowledge & 510 & 475 & & 488 & 458 & \\
\hline School & $235(46.1)$ & $252(53.1)$ & n.s. & $243(49.8)$ & $266(58.1)$ & n.s. \\
\hline Parents & $50(9.8)$ & $55(11.6)$ & n.s. & $94(19.3)$ & $74(16.2)$ & n.s. \\
\hline Brother/Sister & $20(3.9)$ & $21(4.4)$ & n.s. & $8(1.6)$ & $11(2.4)$ & n.s. \\
\hline Friends & $99(19.4)$ & $92(19.4)$ & n.s. & $78(16.0)$ & $59(12.9)$ & n.s. \\
\hline TV and Magazines & $65(12.7)$ & $55(11.6)$ & n.s. & $41(8.4)$ & $33(7.2)$ & n.s. \\
\hline Internet & $134(26.3)$ & $113(23.8)$ & n.s. & $71(14.5)$ & $56(12.2)$ & n.s. \\
\hline Others & $16(3.1)$ & $9(1.9)$ & n.s. & $9(1.8)$ & $9(2.0)$ & n.s. \\
\hline
\end{tabular}

The top of each item column is the total number of respondents. The significant level is 0.05 .

\section{Discussion}

As a result of the study, few students answered that they had a sufficient knowledge and looking at either correct or incorrect answer to the question on condom usage, actually not so many students had the correct sexual knowledge de- 
spite most students responded that they received sex education.

Also, regarding "acquainted (having knowledge of its symptom and infection rout) with sexually transmitted diseases" all diseases except chlamydia in boys did not exceed half in both boys and girls. However, as to most diseases students who responded "I know" were significantly more at the third-grade times after an educational intervention than the second-grade times.

Regarding "acquainted (having knowledge of its way to use and success probability of contraception) contraceptive methods" condom was more than $90 \%$ in both grades and both boys and girls, oral contraceptive pill was more than $70 \%$, and students who responded "I know" on most contraceptive methods were significantly more at the third-grade times after an educational intervention than the second-grade times. Thus increased number of knowledgeable students by only one intervention suggests that increasing number of interventions increases knowledgeable students and its possibility for promoting the diffusion of knowledge.

Most students in both grades and both boys and girls responded that they acquired sexual information from school followed by friends and the Internet. Students who acquire from the Internet which is globally concerned as a problem of influences on young people were more in boys than girls (Strasburger, 2012; Brown \& Keller, 2000). Anh D. Ngo, et al. (Ngo, Ross, \& Ratliff, 2008) conducted a survey with multiple-ages young people from 15- to 19-year-old and reported the number of uses of the Internet for acquiring sexual information. However, in results of the survey of only from the second-grade to the third-grade students in Japan the students who use the Internet for acquiring sexual information was $12 \%$ - $24 \%$ that was slightly different from previous studies. This is considered to be due to that our study was conducted by the unprecedented survey of narrowing analysis subjects down to specific ages. In previous studies, as subjects from the third-grade of junior high school to college students and nonstudents were included the lifestyles of each subject were considered to vary widely. That is, it is considered that late-teens may include the late-third-grade high school students, high school graduates, and even nonstudents or working young people who start increasingly to acquire sexual information from the Internet. When we analyze adolescent sexual behavior or awareness, it is necessary to conduct a survey longitudinally or by each subject's background paying much further attention on that only one year time lag or school attendance status may make a big difference. This will make us possible to verify when, under what kind of background and what kind of behavior the adolescents will initiate accordingly. In the future it will be necessary to compare between the second-grade and the third-grade students and between high school attending students and nonstudents. From the results of our study we may say that the situation in Japan has not become yet such a stage that uncensored information spreads unlimitedly among whole high school students. However, it may be expected in the future that sexual information sources for high school students will change in parallel with the usage and frequency of personal owned 
electric communication devises including a smart phone. Also, it will be considered in the future that lowering trend in age of mainstream of acquiring sexual information through the Internet. Therefore, it will be effective to provide education on the usage of the Internet promptly and to enforce the age limit system domestically to access and browse online information.

Additionally, since participating students think it is the best way to acquire the information from school, deep understanding of sex education within the whole school and upskilling high school teachers in sex education are desirable. It is difficult to check and correct individual differences of the level of comprehension as media such as the Internet, magazines and TV feed information unilaterally. Also, the information from friends of the same generation may not be much difference from the level of own knowledge and may not be the right piece of information. However, acquiring the information from teachers can be considered as the best way because teachers may be able to check the level of comprehension of high school students and possibly to provide an education that is adjusted to an individual level. Furthermore, although a number of boys who responded that they should acquire the information from parents were limited to few, girls listed parents following school and it was considered that there was a difference between boys and girls in needs of sex education at home. Especially, an education by mother is considered to be effective to change girls' awareness and behavior as it has been reported that mother's intervention or prohibition on sexual behavior delays the initiation of sexual activities (Sieving, McNeely, \& Blum, 2000; Hoff, Greene, \& Davis, 2003; Trinh, Steckler, Ngo, \& Ratliff, 2009; Tseng, Weng, Kuo, Chou, Yang, \& Chiang, 2015).

\section{Conclusion}

Most participating students responded that they received sex education, but not so many of them actually had correct knowledge. In our study that was conducted by the unprecedented survey of narrowing analysis subjects down to specific ages (the second-grade high school students), students who used the Internet as a source of sexual information were not the most which was a different result of previous studies. Since in both boys and girls, there were many opinions that the sexual information should be acquired from school, this suggested that the expectation of high school students toward his or her school and teachers was high in both boys and girls. Among girls, parents were listed following school for a source for the sexual information and therefore we may say that there is a difference between boys and girls in needs of sex education at home. For the future, upskilling teachers and parents in sex education at school and home is expected.

\section{Acknowledgements}

We are grateful for the understanding and cooperation of the participating high schools' staff members, students and their parents in conducting this study. 
This study is a part of "Determinants of Sexual Awareness of High School Students-Survey and Intervention to High School Junior Students" (16K04045) which has been conducted under Grant-in-Aid for Scientific Research (C) Japan Society for the Promotion of Science.

\section{Conflicts of Interest}

The authors declare no conflicts of interest regarding the publication of this paper.

\section{References}

Arulogun, O. S., Ogbu, I. A., \& Dipeolu, I. O. (2016). Influence of Internet Exposure on Sexual Behaviour of Young Persons in an Urban District of Southwest Nigeria. The Pan African Medical Journal, 25, 261. https://doi.org/10.11604/pamj.2016.25.261.2630

Bleakley, A., Hennessy, M., Fishbein, M., \& Jordan, A. (2009). How Sources of Sexual Information Relate to Adolescents' Belief about Sex. American Journal of Health Behavior, 33, 37-48. https://doi.org/10.5993/AJHB.33.1.4

Brown, J. D., \& Keller, S. N. (2000). Can the Mass Media Be Healthy Sex Educators? Family Planning Perspectives, 32, 255-256. https://doi.org/10.2307/2648180

Buhi, E. R., Daley, E. M., Fuhrmann, H. J., \& Smith, S. A. (2009). An Observational Study of How Young People Search for Online Sexual Health Information. Journal of American College Health, 58, 101-111. https://doi.org/10.1080/07448480903221236

Hoff, T., Greene, L., \& Davis, J. (2003). National Survey of Adolescents and Young Adults: Sexual Health Knowledge, Attitudes, and Experiences. Menlo Park, CA: Kaiser Family Foundation.

Japanese Association of "Yogo" Teacher Education. http://yogokyoyu-kyoiku-gakkai.jp/wp/?page_id=1520

Japanese Ministry of Health, Labor and Welfare (2012). Healthy Parents and Children 21. https://www.mhlw.go.jp/english/wp/other/councils/sukoyaka21/index.html

Liliana Escobar-Chaves, S., Tortolero, S., Markham, C., Low, B., Eitel, P., \& Thickstun, P. (2005). Impact of the Media on Adolescent Sexual Attitudes and Behaviors. Pediatrics, 116, 303-326.

Ngo, A., Ross, M., \& Ratliff, E. (2008). Internet Influence on Sexual Practice among Young People in Hanoi, Vietnam. Culture, Health \& Sexuality, 10, S201-S213. https://doi.org/10.1080/13691050701749873

Sieving, R. E., McNeely, C. S., \& Blum, R. W. (2000). Maternal Expectations, Mother-Child Connectedness, and Adolescent Sexual Debut. Archives of Pediatrics and Adolescent Medicine, 154, 809-816. https://doi.org/10.1001/archpedi.154.8.809

Song, S., Kawabata, T., Meijin, Y. I., Li, K. H., Sakai, C., Tsujimoto, S., Nakamura, H., \& Chen, X. (2012). Preliminary Study on the Effects of Contact with Sexual Content on the Internet on Adolescent Sexual Behavior. Japanese Journal of School Health, 54, 152-161.

Stevens, R., Gilliard-Matthews, S., Dunaev, J., Todhunter-Reid, A., Brawner, B., \& Stewart, J. (2017). Social Media Use and Sexual Risk Reduction Behavior among Minority Youth: Seeking Safe Sex Information. Nursing Research, 66, 368-377. https://doi.org/10.1097/NNR.0000000000000237

Strasburger, V. C. (2012). Adolescents, Sex, and the Media. Adolescent Medicine: State of the Art Reviews, 23, 15-33. 
Strasburger, V. C., Wilson, B. J., \& Jordan, A. (2009). Children, Adolescents, and the Media (2nd Ed.). Thousand Oaks, CA: Sage.

Trinh, T., Steckler, A., Ngo, A., \& Ratliff, E. (2009). Parent Communication about Sexual Issues with Adolescents in Vietnam: Content, Contexts, and Barriers. Abingdon-on-Thames: Taylor \& Francis.

Tseng, Y. H., Weng, C. S., Kuo, S. H., Chou, F. H., Yang, Y. H., \& Chiang, L. C. (2015). Gender Differences? Internet Use and Parent-Child Communication about Sex toward Sexual Attitudes among Early Adolescents in Taiwan. Journal of Nursing Research, 23, 125-134.

UNFPA, The State of World Population. (2013). Motherhood in Childhood-Facing the Challenge of Adolescent Pregnancy.

United Nations Department of Economic and Social Affairs Population Division (2011). http://www.un.org/en/development/desa/population/

Wartella, E., Rideout, V., Zupancic, H., Beaudoin-Ryan, L., \& Lauricella, A. (2015). Teens, Health, and Technology: A National Survey. Chicago, IL: Center on Media and Human Development at Northwestern University.

Watanabe, K. (2016). The Cross Sectional Study on the Association between Sexual Awareness and Cognitive Social Capital among High School Students in Ho Chi Minh City, Vietnam. Advances in Sexual Medicine, 6, 33-39.

https://doi.org/10.4236/asm.2016.63005

Watanabe, K., Kaneko, Y., Fujita, K., \& Motohashi, Y. (2014a). The Association between Awareness of Sexual Behavior and Cognitive Social Capital among High School Students in Vietnam. Open Journal of Preventive Medicine, 4, 116-122.

Watanabe, K., Saruta, R., \& Kato, N. (2014b). Sources of Sexual Knowledge among Vietnamese High School Students. Advances in Reproductive Sciences, 2, 83-87.

World Health Organization (WHO) (2011). Unsafe Abortion: Global and Regional Estimates of the Incidence of Unsafe Abortion and Associated Mortality in 2008 (6th Ed.). Geneva: WHO. 